\title{
Short-term treatment with metformin reduces hepatic lipid accumulation but induces liver inflammation in obese mice
}

\author{
Alexandre Abilio de Souza Teixeira ${ }^{1}$. Camila O. Souza ${ }^{1} \cdot$ Luana A. Biondo $^{1} \cdot$ Loreana Sanches Silveira $^{2}$. \\ Edson A. Lima ${ }^{1} \cdot$ Helena A. Batatinha ${ }^{1}$. Adriane Pereira Araujo ${ }^{1}$. Michele Joana Alves ${ }^{1}$. Sandro Massao Hirabara ${ }^{4}$. \\ Rui Curi ${ }^{3,4}$. José Cesar Rosa Neto ${ }^{1}$
}

Received: 21 November 2017 / Accepted: 12 January 2018 / Published online: 15 February 2018

(c) Springer International Publishing AG, part of Springer Nature 2018

\begin{abstract}
The study aimed to evaluate the metabolic and inflammatory effects of short-term treatments (10 days) with metformin (MET) on the NAFLD caused by a high-fat diet (HFD) in C57BL/6 mice. After the treatment, histological liver slices were obtained, hepatocytes and macrophages were extracted and cultured with phosphate buffered saline, LPS $(2.5 \mu \mathrm{g} / \mathrm{mL})$ and MET $(1 \mu \mathrm{M})$ for $24 \mathrm{~h}$. Cytokine levels were determined by ELISA. NAFLD caused by the HFD was partially reduced by MET. The lipid accumulation induced by the HFD was not associated with liver inflammation; however, MET seemed to promote pro-inflammatory effects in liver, since it increased hepatic concentration of IL-1 $\beta$, TNF- $\alpha$, IL-6, MCP-1 and IFN- $\gamma$. Similarly, MET increased the concentration of IL-1 $\beta$, IL-6 in hepatocyte cultures. However, in macrophages culture, MET lowered levels of IL-1 $\beta$, IL-6 and TNF- $\alpha$ stimulated by LPS. Overall, MET reduced liver NAFLD but promoted hepatocyte increase in pro-inflammatory cytokines, thus, leading to liver inflammation.
\end{abstract}

Keywords Obesity $\cdot$ Metformin $\cdot$ Inflammation $\cdot$ Liver

\section{Introduction}

The liver is a complex metabolic organ, and a classical example of the tight interaction between the immune system and metabolism. The liver's metabolic role is coordinated by hepatocytes, the most abundant cell type, but the cells responsible for the initial immune responses to stimuli,

Electronic supplementary material The online version of this article (https://doi.org/10.1007/s10787-018-0443-7) contains supplementary material, which is available to authorized users.

Alexandre Abilio de Souza Teixeira

alexandreast@gmail.com

1 Immunometabolism Research Group, Department of Cell Biology and Development, Institute of Biomedical Sciences, University of São Paulo, São Paulo, SP, Brazil

2 Exercise and Immunometabolism Research Group, Department of Physical Education, UNESP, Presidente Prudente, Brazil

3 Department of Physiology and Biophysics, Institute of Biomedical Sciences, University of São Paulo, São Paulo, SP, Brazil

4 Cruzeiro do Sul University, São Paulo, SP, Brazil
Kupffer cells (KC) and hepatic satellite cells (HSc), only constitute $15 \%$ of the liver cell population. (Nati et al. 2016). Pathological conditions promote the migration of immune cells, which, besides changes to the proportion and subtypes of cells in the liver, could also lead to the maintenance of a chronic inflammatory state (Fader et al. 2015; Mikami et al. 2014).

Nonalcoholic fatty liver disease (NAFLD), characterized by an accumulation of fat droplets in hepatic parenchyma, is the most common chronic liver disease (Tiniakos et al. 2010). NAFLD has been highly associated with other metabolic diseases, such as obesity, insulin resistance, type 2 diabetes and cardiovascular diseases (Love-Osborne et al. 2008). It was also observed that long-term NAFLD can progress into harmful kinds of liver disease, like nonalcoholic steatohepatitis (NASH), cirrhosis, hepatocellular carcinoma and liver failure (McCullough 2004).

The western diet, rich in fatty acids, can trigger the process of apoptosis, necrosis, oxidative stress, and lipid peroxidation in the liver (Casas et al. 2014; Yadav and Ramana 2013). Although the most accepted hypothesis for the NAFLD pathogenesis points to the excess of free fatty acids (FFA) caused by peripheral insulin resistance as a trigger 
for higher triacylglycerol incorporation (Adams et al. 2005; Teixeira et al. 2016) and impaired oxidation functions (Berlanga et al. 2014), it is well known that inflammation could promote metabolic alterations in the liver.

In fact, low grade inflammation (LGI), observed in obesity and insulin-resistant patients (Brestoff and Artis 2015; McNelis and Olefsky 2014), seems to have an important role in the progression of NAFLD (Xu et al. 2015a). LGI is responsible for a low sustained exacerbation of cytokines, chemokines, adipokines and acute phase proteins, which increase the recruitment of immune cells and also seem to impair insulin sensitivity and oxidative metabolism in the liver (Liu et al. 2016; Nati et al. 2016).

Until the present moment, no drug has been approved as a treatment for NAFLD. Nevertheless, Metformin (MET) activates AMPK, reducing glucose production in the liver and improving glucose and fatty acid uptake, as well as their oxidation in skeletal muscle (Viollet et al. 2009). Moreover, MET has been described as being able to induce an anti-inflammatory response by (1) decreasing the levels of inflammatory cytokines in macrophages activated by lipopolysaccharide (LPS) (Kelly et al. 2015; Kim et al. 2014), (2) impairing monocyte-macrophage differentiation (Vasamsetti et al. 2015) and (3) increasing M2 (anti-inflammatory) macrophages activation (Chen et al. 2015).

Although the use of MET as a treatment for type 2 diabetes is well established, its actions over hepatic illnesses have not been widely investigated. Thus, the aim of this study was to evaluate the effects of short-term metformin treatments (10 days) on NAFLD caused by a high-fat diet in mice.

\section{Materials and methods}

\section{Animal procedure}

Male C57BL/6 J mice maintained in standard conditions were fed with a high-fat diet (HFD, caloric content: 59\% fat, $15 \%$ proteins, $26 \%$ carbohydrate) (Reeves et al. 1993) or a standard diet (SD, caloric content: $9 \%$ fat, $15 \%$ protein, 76\% carbohydrate) (Reeves et al. 1993) for 12 weeks. In the last 10 days, the mice received phosphate-buffered saline (PBS) or metformin ( $300 \mathrm{mg} / \mathrm{kg}$ of body weight) daily by oral administration (gavage), based on previous studies (Souza-Mello et al. 2010; Spruss et al. 2012). The body weight was evaluated weekly for 12 weeks, then the mice were fasted (4 h), culled, and the samples of blood (total cholesterol: Labtest ${ }^{\circledR}$, Lagoa Santa, MG, Brazil) and tissue (liver, adipose tissue and skeletal muscle) were collected. Adipose tissue index was calculated as sum of epididymal, subcutaneous, and retroperitoneal adipose tissue weight. The experimental protocols were approved by the Ethics Committee for Animal Experimentation, Institute of Biomedical
Sciences, registered under the number 050 in the fls. 05 of book 03 .

\section{Histological analyses}

Liver biopsies $(50 \mathrm{mg})$ were obtained carefully excised using scissors following by fixation $4 \%$ paraformaldehyde $(\mathrm{w} / \mathrm{v}), \mathrm{pH}$ 7.4. The samples were dehydrated in absolute ethanol, diaphanization in xylol and for last, embedded in paraffin (Paraplast X-TRA, SIGMA-ALDRICH). The sections of $5 \mu \mathrm{m}$ were mounted onto slides Starfrost ${ }^{\circledR}$ (Knittel Glass). Deparaffinized and hydrated sections were stained with hematoxylin $(\mathrm{H})$ and counterstained with eosin $(\mathrm{E})$ and photographed under light microscopy (Olympus).

\section{Picro sirius red}

The 5- $\mu \mathrm{m}$ sections previously deparaffinized were hydrated during $5 \mathrm{~min}$ in running water followed for $1 \mathrm{~h}$ at room temperature of staining by Picro Sirius red dye. The slides were mounted with Permount (Tuluene Solution, Fischer Scientific).

\section{Oil red 0}

For Oil Red O (ORO) staining, the fresh liver samples were cryo-preserved with isopentane and freezing into liquid nitrogen. Before cryostat sections set to $-21^{\circ} \mathrm{C}$ were obtained, the samples were covered with Tissue-Tek. Sections of $7 \mu \mathrm{m}$ were hydrated in phosphate buffer during $5 \mathrm{~min}$ and fixed for $30 \mathrm{~min}$ at room temperature in buffered formalin (4\%), ph 7.4. The staining protocol was performed adapted from VanSaun (2009). After fixation, the slides were rinsed in running water for $10 \mathrm{~min}$ followed by $60 \%$ isopropanol for $5 \mathrm{~min}$. The working solution of ORO was directly applied into each section during $1 \mathrm{~h}$ at room temperature. The working solution was prepared from stock solution, consisting of $5 \mathrm{~g}$ ORO (Sigma, Aldrich, St. Louis, MO) in 100\% isopropanol, at 3:2 with distilled water. After staining, slides were immersed in $60 \%$ isopropanol following by $5 \mathrm{~min}$ with distilled water. Mayer's hematoxylin was used to counterstaining, tris-buffered saline during $1 \mathrm{~min}$ and distilled water by $5 \mathrm{~min}$. After, the slides were mounted with glycerol.

All images were acquired using Image ProPlus v.5.2 (Media Cybernetics, Bethesda, MD, USA) digital camera system coupled to a light microscope (Olympus).

\section{Glucose tolerance tests}

The glucose tolerance tests were performed at the seventh (before metformin treatment) and 11th week (after 8 days 
with metformin treatment), in which blood samples were collected 0 (basal), 15, 30, 60 and 90 min after the D-glucose ( $2 \mathrm{~g} / \mathrm{kg}$ body weight) intraperitoneal injection (Bergmeyer and Bernet 1974). The levels of plasma glucose were measured using an Accu-Chek ${ }^{\circledR}$ performa glucometer $\left(\mathrm{ROCHE}^{\circledR}\right.$, São Paulo, SP, Brazil), and the difference of glycemia before and after glucose administration over time was used to calculate the area under the curve (AUC).

\section{Enzyme-linked immunosorbent assay (ELISA)}

Liver retroperitoneal adipose tissue and gastrocnemius muscle samples $(80-100 \mathrm{mg})$ were carefully homogenized in RIPA buffer $(0.625 \%$ Nonidet P-40, $0.625 \%$ sodium deoxycholate, $6.25 \mathrm{mM}$ sodium phosphate, and $1 \mathrm{mM}$ EDTA at $\mathrm{pH}$ 7.4) containing $10 \mu \mathrm{g} / \mathrm{mL}$ of protease inhibitor cocktail (Sigma-Aldrich $^{\circledR}$, St. Louis, Missouri, USA). The homogenate supernatant was utilized to measure total protein concentration by Bradford assay (Bio-Rad ${ }^{\circledR}$, Hercules, CA, USA) and to determine expression of IL- $1 \beta$, TNF- $\alpha$, IL-6, IL-12, MCP-1, IFN- $\gamma$, IL-1Ra, IL-10, IL-4, adiponectin and FGF21 by ELISA (DuoSet ELISA ${ }^{\circledR}$, R\&D Systems, Minneapolis, MN, USA).

\section{RNA isolation, reverse transcription, and real-time PCR}

The expression of hepatic genes related to metabolic and inflammatory factors was assessed by qRT-PCR with a SYBR Green marker. For this reason, total RNA was extracted as described by Chomczynski and Sacchi (1987), quantified in a spectrophotometer $(260 \mathrm{~nm})$, and cDNA was synthesized from the total RNA using reverse transcriptase. The sequences of the primers are shown in Supplementary Table 1; gene expression was quantified by the comparative method using the expression of GAPDH or RPL-19 as standard (Livak and Schmittgen 2001).

\section{Western blotting (WB)}

The total protein extracted $(25 \mu \mathrm{g})$ from the liver, retroperitoneal adipose tissue and gastrocnemius muscle was diluted in Laemmli buffer, subjected to electrophoresis in a SDS-polyacrylamide gel and transferred to a nitrocellulose membrane. The membranes were incubated with antibodies against Total AMPK (1:1000), Phosphorylate AMPK (1:1000), PPAR- $\gamma$ (1:1000), Total ACC (1:1000), Phosphorylate ACC (1:1000), FAS (1:1000) and FABP4 (1:1000) (Cell Signaling Technologies, USA) or $\beta$-tubulin (1:1000) (Santa Cruz Biotechnology ${ }^{\circledR}$, USA) followed by anti-IgG peroxidase-conjugated antibody, and then incubated with the peroxidase substrate (ECL kit, Biorad ${ }^{\circledR}$, USA) and exposed to X-ray film.

Table 1 Effect of 10-day metformin treatment on body weight (BW), tissue weight AND total cholesterol

\begin{tabular}{|c|c|c|c|c|}
\hline & SD & SD M & HFD & HFD M \\
\hline Initial BW (g) & $23.35 \pm 0.57(n=12)$ & $\begin{array}{l}23.70 \pm 0.3019 \\
(n=12)\end{array}$ & $23.69 \pm 0.26(n=12)$ & $23.14 \pm 0.79(n=12)$ \\
\hline Tenth week BW (g) & $29.860 \pm 0.84(n=12)$ & $\begin{array}{l}29.74 \pm 0.9590 \\
(n=12)\end{array}$ & $40.46 \pm 0.79^{\mathrm{a}, \mathrm{b}}(n=12)$ & $40.50 \pm 1.61^{\mathrm{a}, \mathrm{b}}(n=12)$ \\
\hline Final BW (g) & $29.46 \pm 0.75(n=12)$ & $28.77 \pm 0.7969(n=12)$ & $42.39 \pm 0.91^{\mathrm{a}, \mathrm{b}}(n=12)$ & $37.92 \pm 1.55^{\mathrm{a}, \mathrm{b}, \mathrm{c}}(n=12)$ \\
\hline Liver weight (g) & $0.990 \pm 0.023(n=12)$ & $1.014 \pm 0.043(n=12)$ & $1.30 \pm 0.058^{\mathrm{a}, \mathrm{b}}(n=12)$ & $\begin{array}{l}1.14 \pm 0.018 \\
(n=12)\end{array}$ \\
\hline Adiposity index (g) & $1.762 \pm 0.214(n=12)$ & $1.578 \pm 0.2194(n=12)$ & $5.109 \pm 0.327^{\mathrm{a}, \mathrm{b}}(n=12)$ & $4.702 \pm 0.245^{\mathrm{a}, \mathrm{b}}(n=12)$ \\
\hline Retroperitoneal adipose tissue (g) & $0.308 \pm 0.033(n=12)$ & $0.281 \pm 0.039(n=12)$ & $0.782 \pm 0.061^{\mathrm{a}, \mathrm{b}}(n=12)$ & $0.7625 \pm 0.029^{\mathrm{a}, \mathrm{b}}(n=12)$ \\
\hline Brown adipose tissue weight $(\mathrm{g})$ & $0.115 \pm 0.011(n=12)$ & $\begin{array}{l}0.1130 \pm 0.007 \\
(n=12)\end{array}$ & $0.166 \pm 0.016^{\mathrm{a}, \mathrm{b}}(n=12)$ & $0.144 \pm 0.012(n=12)$ \\
\hline Gastrocnemius muscle (g) & $\begin{array}{l}0.2970 \pm 0.011 \\
(n=12)\end{array}$ & $\begin{array}{l}0.2951 \pm 0.006 \\
(n=12)\end{array}$ & $\begin{array}{l}0.3034 \pm 0.005 \\
(n=12)\end{array}$ & $\begin{array}{l}0.2878 \pm 0.009 \\
(n=12)\end{array}$ \\
\hline Total cholesterol (mg/dL) & $139.0 \pm 15.27(n=8)$ & $\begin{array}{l}173.4 \pm 14.07 \\
(n=8)\end{array}$ & $204.5 \pm 16.07^{\mathrm{a}}(n=7)$ & $182.8 \pm 10.38(n=8)$ \\
\hline
\end{tabular}

C57BL/6 mice were fed with a standard diet (SD) or a high-fat diet (HFD), and either treated with metformin (SDM; HFDM) or PBS as placebo The data are presented as the mean \pm SEM

${ }^{\mathrm{a}} p<0.05$ versus SD

${ }^{\mathrm{b}} p<0.05$ versus SDM

${ }^{\mathrm{c}} \mathrm{HFD}$ versus HFDM (Two-way ANOVA followed by Bonferroni correction) 

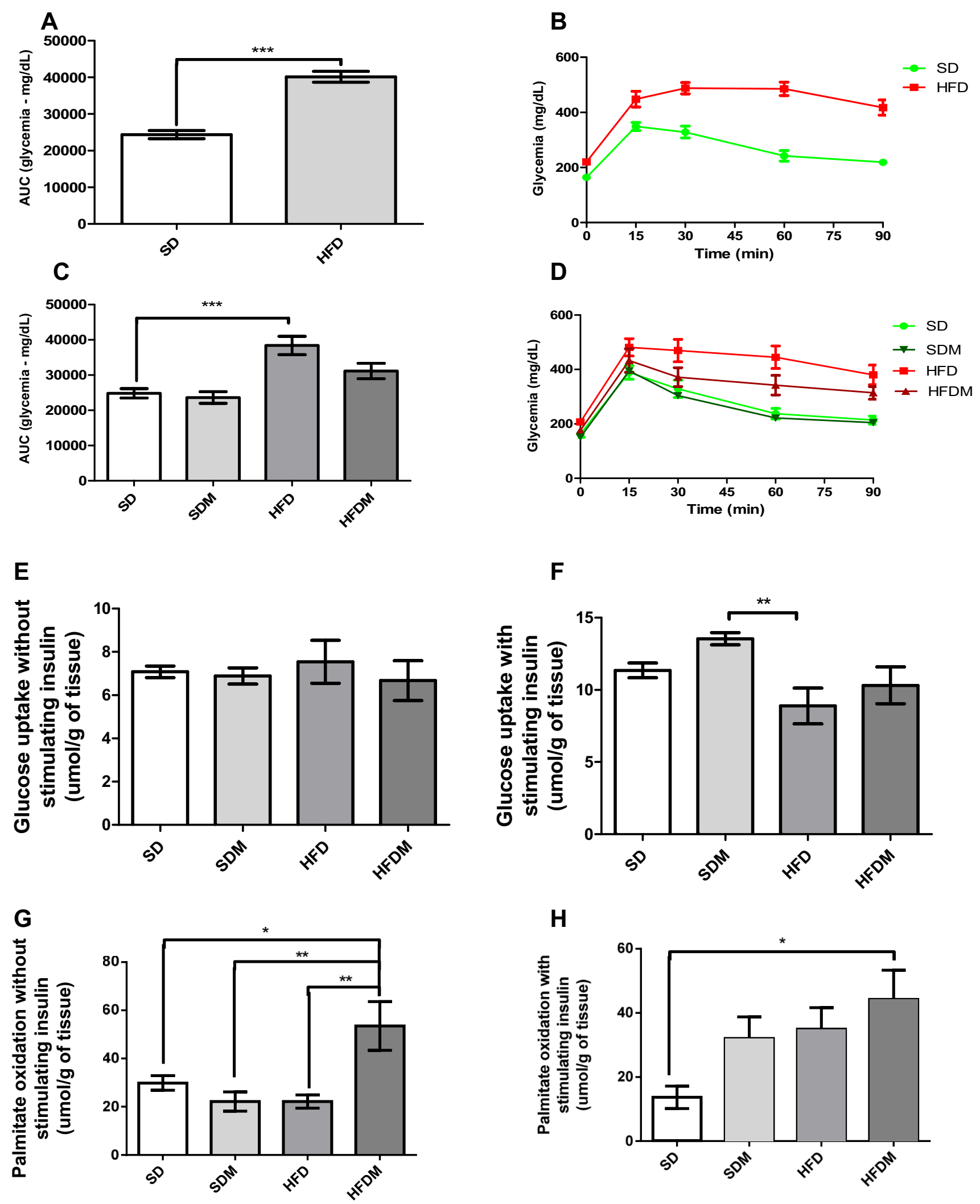
4Fig. 1 Variation in glycemia in the glucose tolerance test in the seventh (a) and 11th week (after 8 days with metformin treatment) (c), respective area under curve (AUC) (b, d), glucose uptake of tissue soleus without stimulating insulin (e), with stimulating insulin (f) Palmitate Oxidation without stimulating insulin (g) and Palmitate Oxidation with stimulating insulin (h) of mice submitted to standard diet (SD) or high fat diet (HFD) for 12 weeks and treated with PBS or metformin (M) $(300 \mathrm{mg} / \mathrm{kg}$ of body weight) for 10 days. The data are mean \pm SEM of 8 animals, $* p<0.05, * * p<0.01$ and $* * * p<0.001$. (Two-way ANOVA followed by Bonferroni)

\section{Insulin Response in Isolated Soleus Muscles}

Soleus muscles were carefully isolated from the culled mice, weighed $(8-10 \mathrm{mg})$, and attached to stainless steel clips to maintain resting tension. The muscles were pre-incubated in Krebs-Ringer bicarbonate buffer containing $5.69 \mathrm{mM}$ glucose and $1 \%$ bovine serum albumin, $\mathrm{pH} 7.4$, and pregassed $\left(95 \% \mathrm{O}_{2}, 5 \% \mathrm{CO}_{2}\right)$ with agitation (100 oscillations/ $\mathrm{min})$. After these procedures, the muscles were transferred to fresh vials containing the same buffer containing $0.3 \mu \mathrm{Ci} / \mathrm{mL}$ D-[U-14C]-glucose and $0.20 \mu \mathrm{Ci} / \mathrm{mL} 2$-deoxy-D-[2,6-3H]glucose in the presence or absence of $7 \mathrm{nM}$ insulin. After the incubation period, the samples were processed to measure the uptake of 2-deoxy-D-[2,6-3H]-glucose, the incorporation of $\mathrm{D}-[14 \mathrm{C}]$-glucose, the synthesis of [14C]-glycogen, and the decarboxylation of $\mathrm{D}-[14 \mathrm{C}]$-glucose, according to the methods described by (Challiss et al. 1983; Espinal et al. 1983; Leighton et al. 1985).

\section{Measurement of palmitic acid oxidation in skeletal muscle}

Oxidation of [U-14C] palmitic acid was evaluated as previously described (Hirabara et al. 2006; Leighton et al. 1985). Skeletal muscle cells were incubated in DPBS containing $25 \mu \mathrm{M}$ palmitic acid, $0.2 \mu \mathrm{Ci} / \mathrm{mL}$ D-[U-14C]palmitic acid and incubated for $2 \mathrm{~h}$ in the absence or presence of etomoxir $(10 \mu \mathrm{M})$ or bromopalmitate $(25 \mu \mathrm{M})$. Phenylethylamine, diluted $1: 1 \mathrm{v} / \mathrm{v}$ in methanol, was added into a separate compartment for $14 \mathrm{CO}_{2}$ adsorption.

\section{Isolation and culture of hepatocytes}

Hepatocytes were isolated according to the method described by (Edwards et al. 2013), in which mice anesthetized by inhalation of isoflurane were subjected to liver perfusion technique in situ (de Morais et al. 2012) with collagenase. After perfusion, the liver was filtered and the hepatocytes obtained were counted by TRIPAN Blue exclusion method. $1 \times 10^{5} / \mathrm{cm}^{2}$ viable cells were plated and cultivated in standard medium containing LPS $(2.5 \mu \mathrm{g} / \mathrm{mL}, E$. coli O111:B4), and/or metformin $(1 \mu \mathrm{M})$. After $24 \mathrm{~h}$, the medium was collected for ELISA and a cell viability assay was performed.

\section{Cell viability (MTT)}

After the stimulation period, hepatocytes were incubated with MTT (bromide 3-(4,5-dimethylthiazol-2-il)-2,5-diphenyltetrazolium) solution $(0.5 \mathrm{mg} / \mathrm{mL})$ for $3 \mathrm{~h}$. The formazan formed was resuspended with isopropanol/ $\mathrm{HCl}(11 \mathrm{M})$ and the absorbance measured $(595 \mathrm{~nm}$ ) was utilized to calculate the cell viability in relation to the absorbance of the control group (100\%). For the treatment of the cells, a dose of $1 \mu \mathrm{M}$ of metformin was used

\section{Extraction and culture of intraperitoneal macrophages}

Macrophages were extracted from the intraperitoneal cavity of C57BL6 mice with RPMI medium and counted in a hemocytometer using TRIPAN Blue exclusion method. $2.5 \times 10^{5} / \mathrm{cm}^{2}$ viable macrophages were exposed to PBS (control) or LPS $(2.5 \mu \mathrm{g} / \mathrm{mL}$, E. coli O111:B4) DMSO or metformin $(1 \mu \mathrm{M})$ for $24 \mathrm{~h}$. Then, the medium and macrophages were collected for further analysis.

\section{Statistical methods}

Normal distribution and variance homogeneity were tested and the appropriate statistical test (two-way ANOVA) was employed. Statistical analysis was carried out with the program GraphPad Prism 5.0, with significance being $<5 \%$ $(p<0.05)$. Data are expressed as mean \pm standard error of the mean (SEM).

\section{Results}

The high fat diet group (HFD) markedly increased the body weight gain of mice (Table 1). This body weight gain caused by the HFD was associated with an increase of liver weight and adiposity (Table 1). As expected by the increase of body weight, the HFD also increased the concentration of total cholesterol (Table 1).

After seven weeks of HFD feeding, an increase of glycemia was observed in the glucose tolerance test (GTT) (Fig. 1b), and this effect could be confirmed by the increased AUC (Fig. 1a). After eight days of metformin (M) treatment, the high fat diet group treated with metformin (HFDM) 

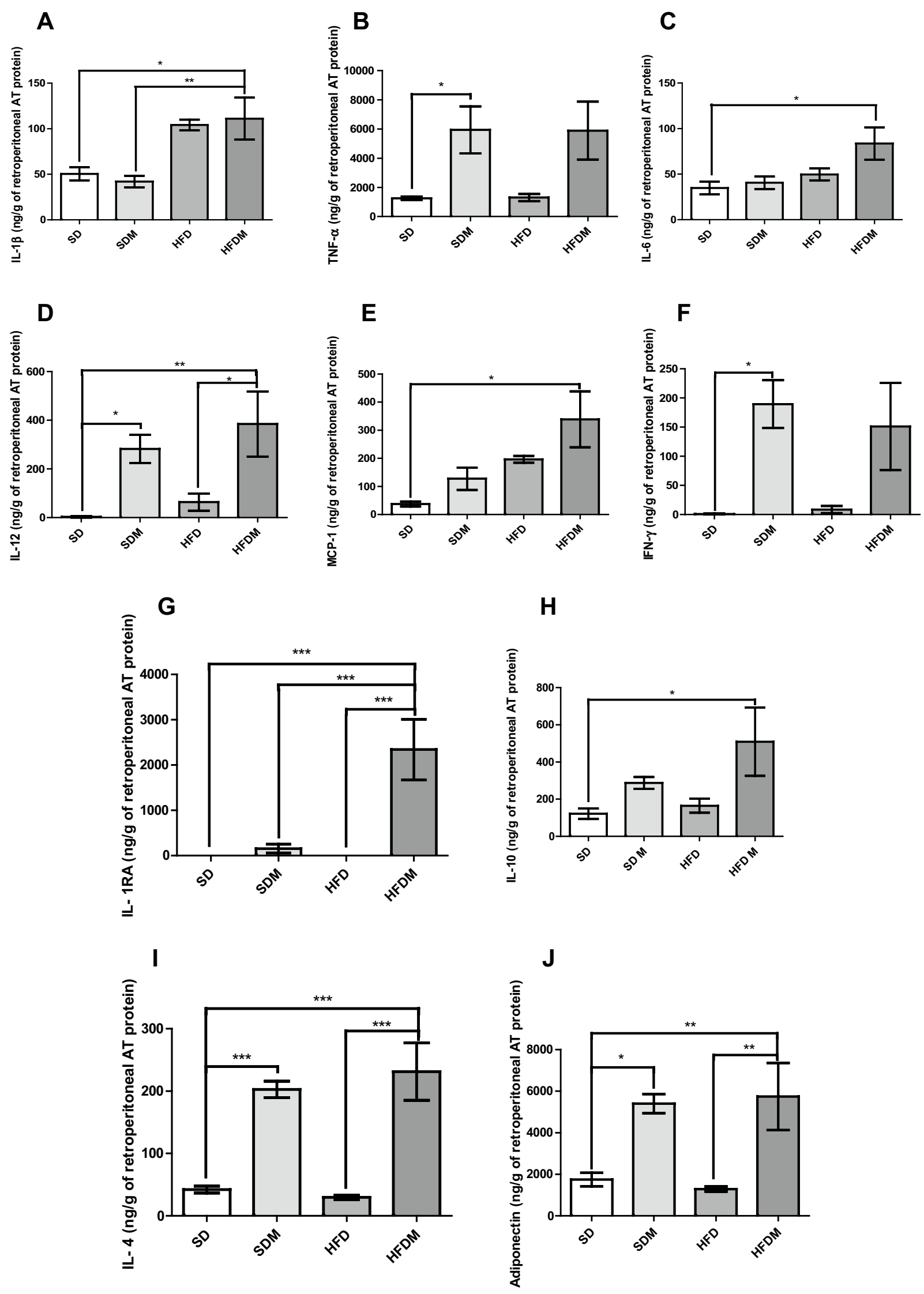
4Fig. 2 Protein expression in retroperitoneal adipose tissue by ELISA of a IL- $1 \beta$, b TNF- $\alpha$, c IL-6, d IL-12, e MCP-1, f IFN- $\gamma, \mathbf{g}$ IL-1RA, h IL-10, i IL-4 and $\mathbf{j}$ Adiponectin of mice submitted to standard diet (SD) or high-fat diet (HFD) for 12 weeks and treated with PBS or metformin (M) (300 mg/kg of body weight) for 10 days. The data are mean \pm SEM of 8 animals, $* p<0.05, * * p<0.01$ and $* * * p<0.001$ (Two-way ANOVA followed by Bonferroni)

presented a lower glycemia in the glucose tolerance test (Fig. $1 \mathrm{C} / \mathrm{D}$ ).

Although the HFD or the metformin treatment had no effect on the weight of the gastrocnemius muscle (Table 1), when compared to the HFD group (Fig. 1f), this drug increased the glucose uptake in skeletal muscle of mice fed with a standard diet. Additionally, increased palmitate oxidation in skeletal muscle in both situations, without insulin stimulus when compared to all the other groups (Fig. 1g) and with the insulin stimulus when compared to the SD (Fig. 1h).

Despite the total weight loss of the HFDM group when compared to the HFD group, when weighed the adiposes tissues we did not observe significant differences between these groups (Table 1). In the retroperitoneal adipose tissue, the protein content of IL- $1 \beta$, TNF- $\alpha$, IL-6, IL-12, MCP-1, IFN- $\gamma$, IL-1RA, IL-10, IL-4 and adiponectin was analyzed (Fig. 2). This analysis allowed us to observe that IL-1 $\beta$ (Fig. 2a), IL-6 (Fig. 2c) and MCP-1 (Fig. 2e) were increased in the HFDM when compared to standard diet groups. Similarly, the TNF- $\alpha$ (Fig. 2b) and IFN- $\gamma$ (Fig. 2f) were increased in SDM when compared to SD, while IL-12 (Fig. 2d) was higher in both groups treated with metformin, when compared to their respective controls.

These results show that metformin increased the concentration of some inflammatory cytokines, however, the same effects of metformin were observed on anti-inflammatory cytokine concentrations. The levels, of IL-1RA (Fig. 2g) and IL-10 (Fig. 2h), were increased in the adipose tissue from HFDM, when compared to SD. Similarly, the concentrations of IL-4 and adiponectin (Fig. 2i, j, respectively) were also increased by metformin in both diets, when compared to their respective controls.

In histological slides of the liver stained with $\mathrm{H} \& \mathrm{E}$, Oil Red and Sirius red, we observed that the lipid accumulation caused by the HFD, was partially reduced in the MET treatment (Fig. 3). The gene expression of AMPK (Fig. 4a), ACC (Fig. 4b) and FAS (Fig. 4c) in the liver was not significantly different. The protein expression of pAMPK (Fig. 5a) increased in the HFDM when compared with HFD, and pACC (Fig. 5b) presented no significant difference. This hepatic steatosis induced by the HFD was not associated with liver inflammation in the HFD. However, metformin seemed to induce liver inflammation, as observed by the higher hepatic concentration of IL-1 $\beta$ (Fig. 6a), TNF- $\alpha$ (Fig. 6b), IL-6 (Fig. 6c), MCP-1 (Fig. 6e) and IFN- $\gamma$ (Fig. 6f) in HFDM mice. Besides its inflammatory effects, metformin also increased the hepatic concentration of IL-10 (Fig. 6h) and adiponectin (Fig. 6j). Nevertheless, the concentration of FGF-21 (Fig. 6k) was decreased in the liver of mice treated with metformin, and the levels of IL-12 (Fig. 6d), IL-1RA (Fig. 6g) and IL-4 (Fig. 6i) were not modulated by the diet nor the -treatment. In the protein expression analyzed by $\mathrm{WB}$, we observed that NF- $\kappa \mathrm{B}$ is increased in the groups treated with metformin (Fig. 61).

Although metformin increased the levels of IL $1 \beta$ in the livers of HFD mice, the hepatic mRNA expression of IL-1 $\beta$ decreased in HFDM when compared with SD. (Figure 7e). However, other inflammatory genes such as IKB- $\alpha$ (Fig. 7c), NF-KB (Fig. 7d), NLRP-3 (Fig. 7f) and Caspase-1 (Fig. 7g), as well as the receptors OCT-1 (Fig. 7a) and OCT-3 (Fig. 7b), were not altered by the diets nor the treatments.

In cultured isolated hepatocytes, the expression of IL-1 $\beta$, IL- 6 and TNF- $\alpha$ stimulated with LPS was analyzed and then treated with $1 \mu \mathrm{M}$ of metformin. We observed that metformin, exclusively, increased the concentration of IL-1 $\beta$ (Fig. 8a) and IL-6 (Fig. 8b), and metformin plus LPS increased the concentration of TNF- $\alpha$ (Fig. 8c). However, in intraperitoneal macrophages, we observed lower levels of IL-1 $\beta$ (Fig. 8d), IL-6 (Fig. 8e) and TNF- $\alpha$ (Fig. 8f) in those cells stimulated with LPS and then treated $1 \mu \mathrm{M}$ of metformin.

\section{Discussion}

We observed that the metformin treatment $(300 \mathrm{mg} / \mathrm{kg}$ of metformin) improved glucose tolerance, weight loss, increased palmitate oxidation in skeletal muscle, alleviated the lipid accumulation in the liver, with a decrease in lipid storage and fibrosis. Furthermore, we observed the different expression of cytokines that occur in different proportion dependent of the tissue, or cell type. A pro-inflammatory profile was found in liver, and we observed that this effect was induced by increased in pro-inflammatory cytokines produced by hepatocytes, while the pro and anti-inflammatory cytokines were increased in adipose tissue, and finally the metformin avoided the pro-inflammatory response in macrophages stimulated with LPS.

Metformin is a well-established drug used for the treatment of type 2 diabetes mellitus (T2D) for decades and appears to also be useful against obesity (Nasri and RafieianKopaei 2014). Specifically, metformin inhibits gluconeogenesis by decreasing the endogenous glucose production by liver (Nasri and Rafieian-Kopaei 2014). Furthermore, this drug improved both insulin sensitivity and $\beta$-cell function (Bi et al. 2013; Patane et al. 2000). An improved glucose tolerance was observed in our model. 

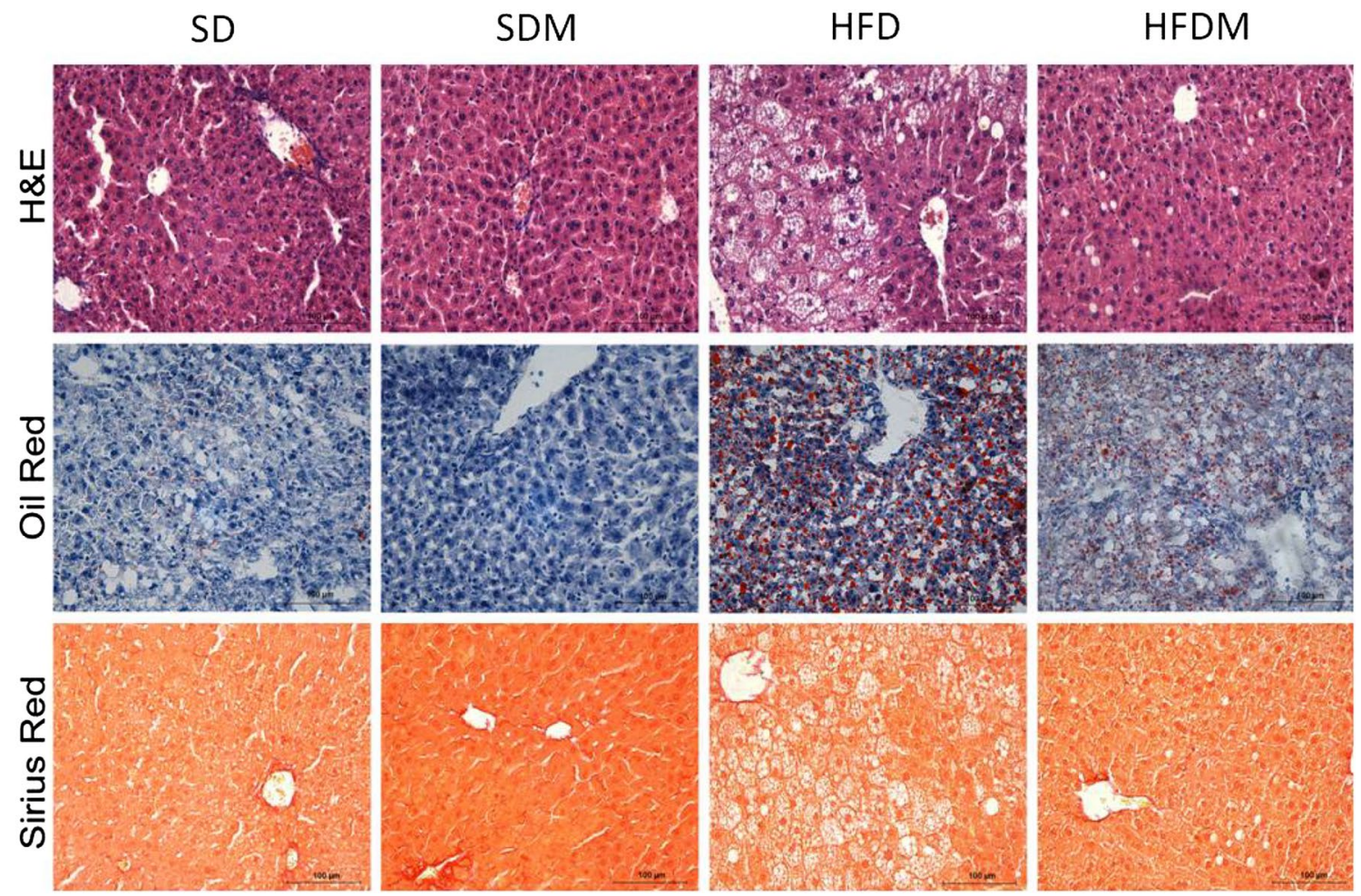

Fig. 3 Histological slices of livers colored by hematoxylin and eosin (H\&E), Oil Red and Sirius Red at $\times 40$ magnification. Livers of mice submitted to standard diet (SD) or high fat diet (HFD) for 12 weeks and treated with PBS or metformin (M) (300 mg/ $\mathrm{kg}$ of body weight) for 10 days. $N=4$ per group
A

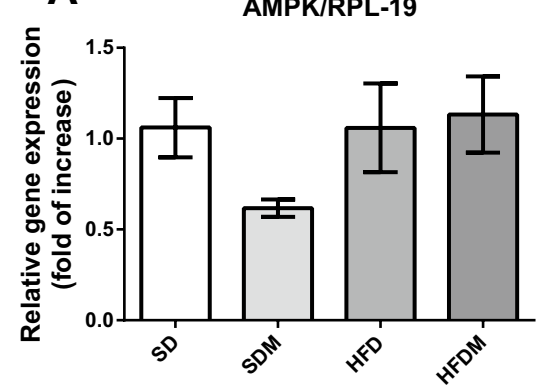

B

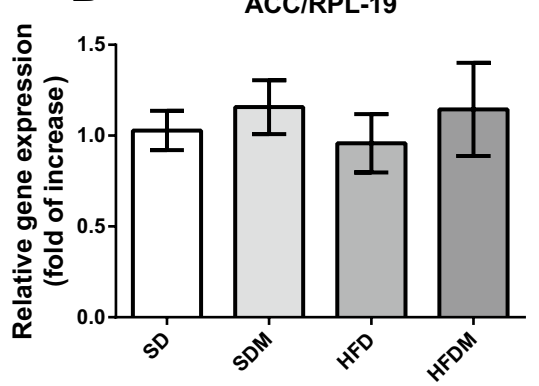

C

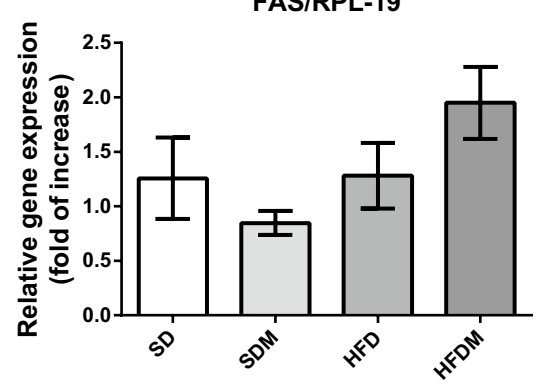

Fig. 4 mRNA expression in liver of a AMPK, b ACC and c FAS of mice submitted to standard diet (SD) or high-fat diet (HFD) for 12 weeks and treated with PBS or metformin (M) $(300 \mathrm{mg} / \mathrm{kg}$ of body weight) for 10 days. The data are mean \pm SEM of 8 animals, $* p<0.05, * * p<0.01$ and $* * * p<0.001$. (Two-way ANOVA followed by Bonferroni)
Moreover, the treatment increased palmitate oxidation in the skeletal muscle of mice submitted to a HFD and treated with metformin. Kitzmann et al. showed that skeletal muscle cells derived from moderately obese T2D patients exhibited decreased beta-oxidation and increased lipid accumulation in response to palmitate overload (Kitzmann et al. 2011). Other studies showed that metformin induced decreases in palmitate uptake (Bogachus and Turcotte 2010) and suppression of lipid accumulation in skeletal muscle, by promoting an increase in fatty acid oxidation (Wang et al. 2014). In fact, some studies show the relation between the abnormalities in skeletal muscle, such as fat accumulation, insulin resistance and loss of skeletal muscle, with the pathogenesis and severity of hepatic steatosis (Flannery et al. 2012; Kitajima et al. 2013; Moon et al. 2013). 
A PAMPK

tAMPK

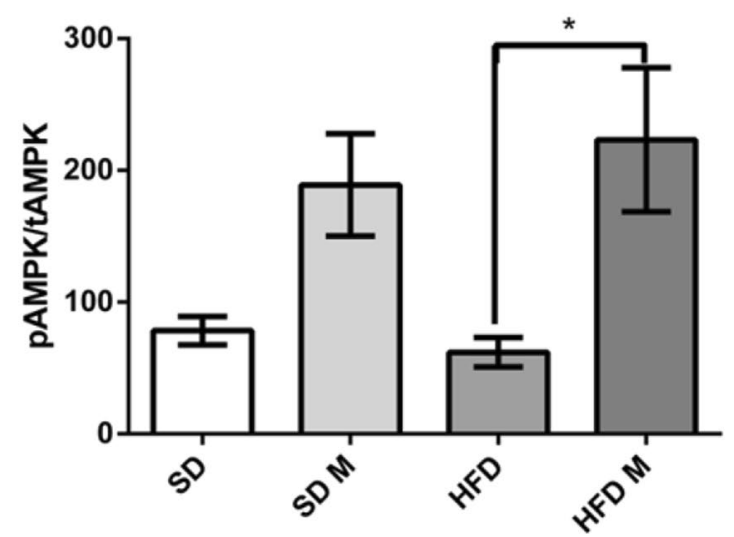

Fig. 5 Protein expression in liver by WB of a AMPK and b ACC of mice submitted to standard diet (SD) or high-fat diet (HFD) for 12 weeks and treated with PBS or metformin (M) $(300 \mathrm{mg} / \mathrm{kg}$ of
B $\quad$ PACC

tACC

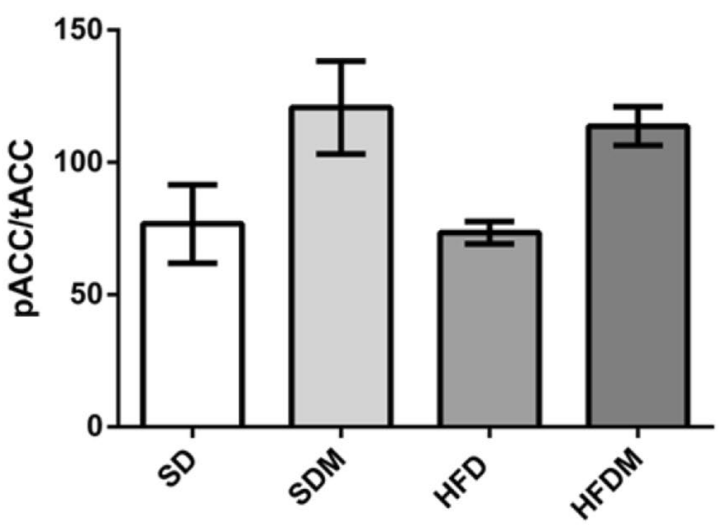

body weight) for 10 days. The data are mean \pm SEM of 6 animals, $* p<0.05, * * p<0.01$ and $* * * p<0.001$. (Two-way ANOVA followed by Bonferroni)
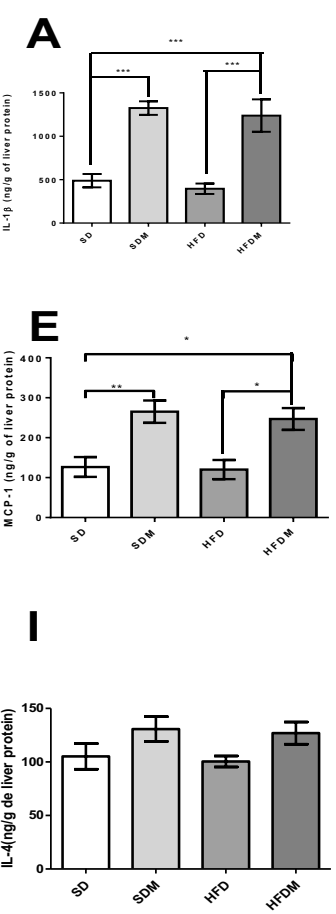

B
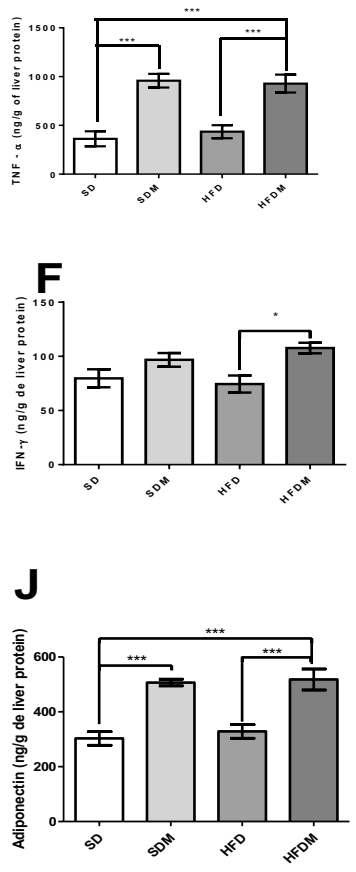

Fig. 6 Protein expression in liver by ELISA of a IL-1 $\beta, \mathbf{b}$ TNF- $\alpha$, $\mathbf{c}$ IL-6, d IL-12, e MCP-1, f IFN- $\gamma$, g IL-1RA, h IL-10, i IL-4, j Adiponectin and $\mathbf{k}$ FGF-21 of mice submitted to standard diet (SD) or high-fat diet (HFD) and Protein expression in liver by WB of phosphorylated and total NF- $\mathrm{KB}$ p65 (L) for 12 weeks and treated with
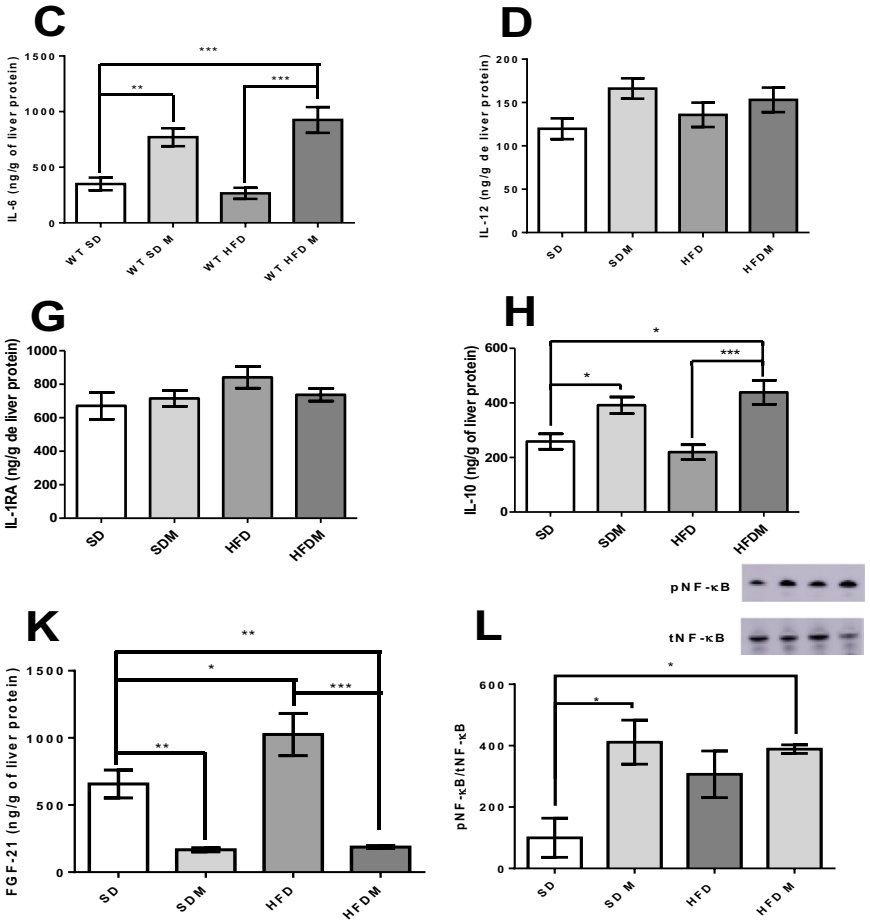

PBS or metformin (M) (300 mg/kg of body weight) for 10 days. The data are mean \pm SEM of 8 animals in ELISA and 4 animals in WB, $* p<0.05, * * p<0.01$ and $* * * p<0.001$ (Two-way ANOVA followed by Bonferroni) 
A

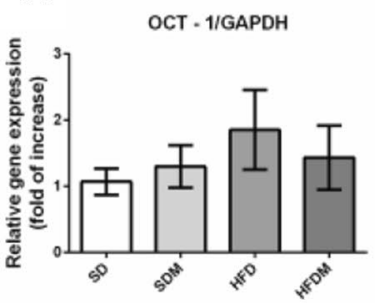

B

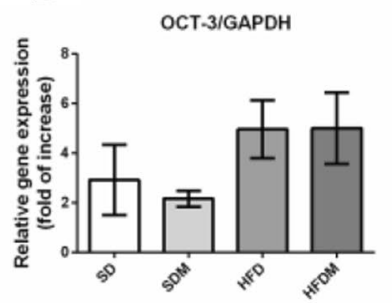

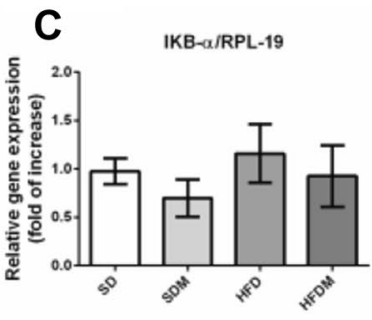

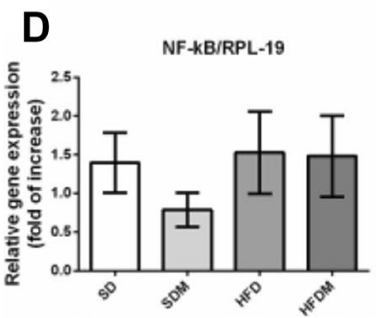

$E$

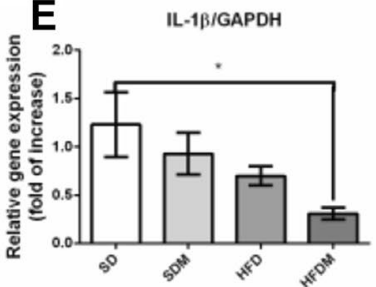

$\mathbf{F}$

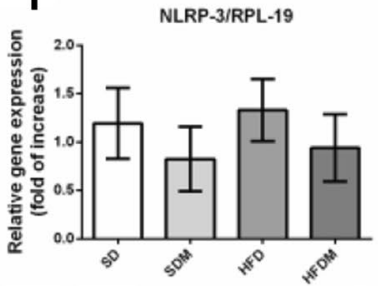

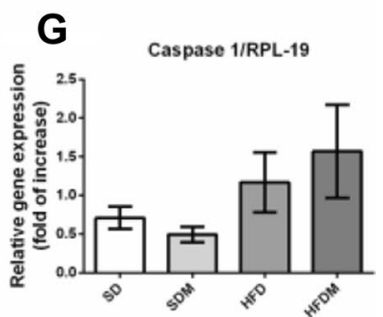

Fig. 7 mRNA expression in liver of a Organic Cation Transporter 1 (OCT-1), b Organic Cation Transporter 3 (OCT-3), c nuclear factor of kappa light polypeptide gene enhancer in B-cells inhibitor, alpha (IкB- $\alpha$ ), $\mathbf{d}$ nuclear factor kappa light chain enhancer of activated $\mathrm{B}$ cells $(\mathrm{NF}-\mathrm{kB})$, e Interleukin $1 \beta$ (IL-1 $\beta$ ), f leucine-rich repeat-contain- ing family protein-3 (NLRP-3) and $\mathbf{g}$ Caspase 1 of mice submitted to standard diet (SD) or high-fat diet (HFD) for 12 weeks and treated with PBS or metformin (M) $(300 \mathrm{mg} / \mathrm{kg}$ of body weight) for 10 days. The data are mean \pm SEM of 8 animals, $* p<0.05$, $* * p<0.01$ and $* * * p<0.001$. (Two-way ANOVA followed by Bonferroni)
A
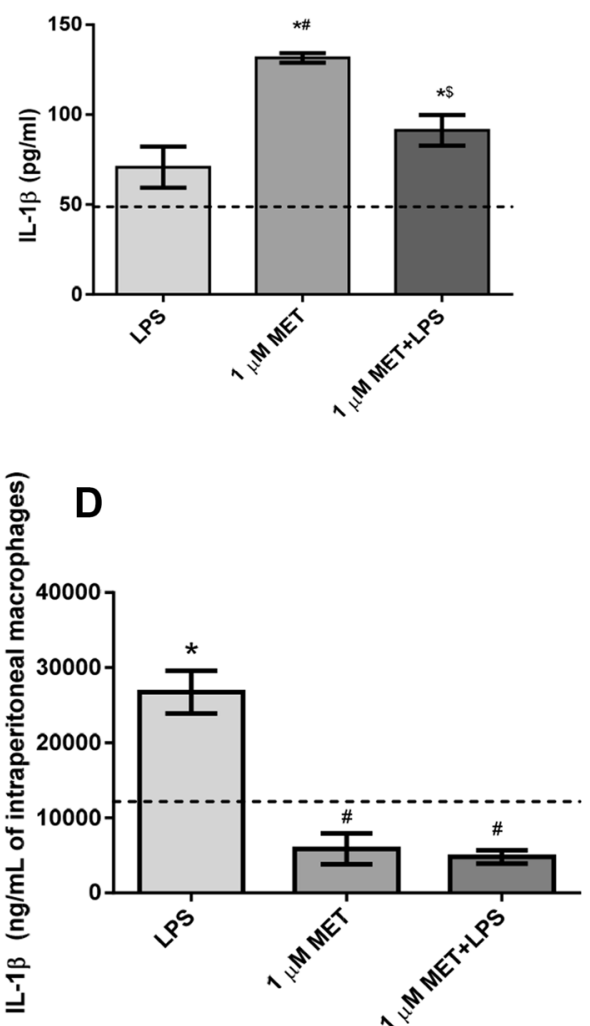

B
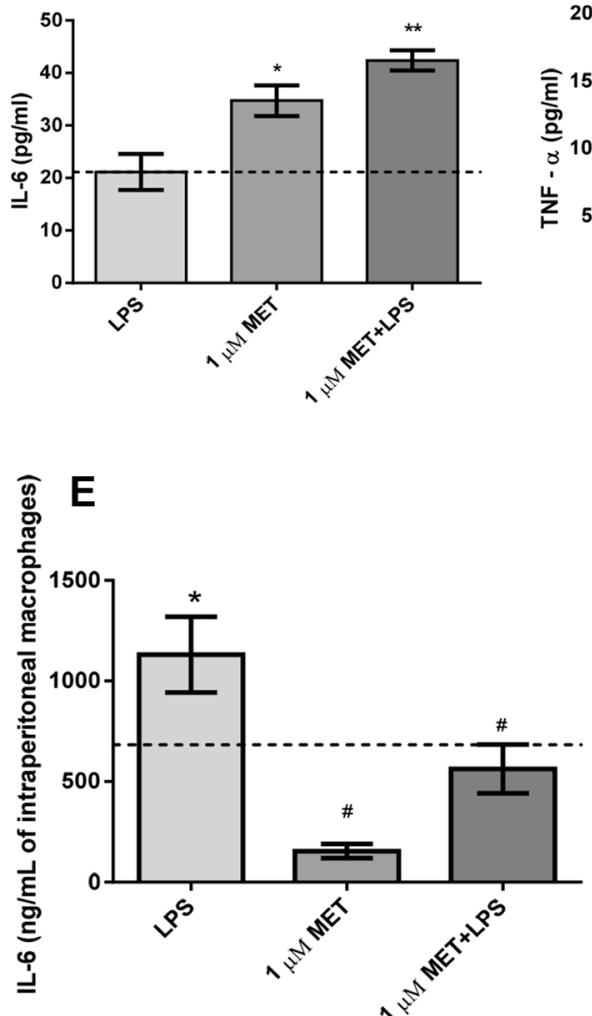

C

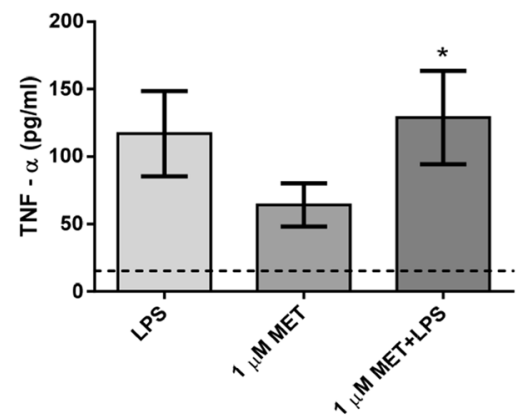

$\mathbf{F}$

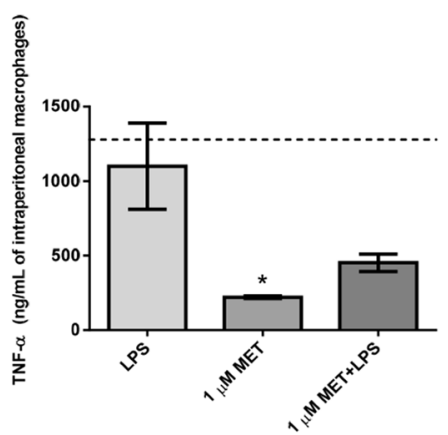

Fig. 8 Protein expression in hepatocytes by ELISA of a IL- $1 \beta, \mathbf{b}$ IL-6 and c TNF- $\alpha$ stimulated with $2.5 \mathrm{ng} / \mathrm{mL}$ LPS and/or treated with $1 \mu \mathrm{M}$ of metformin and protein expression in intraperitoneal macrophages by ELISA of $\mathbf{d}$ IL- $1 \beta$, e IL- 6 and $\mathbf{f}$ TNF- $\alpha$ stimulated with $2.5 \mathrm{ng} / \mathrm{mL}$ LPS and/or treated with $1 \mu \mathrm{M}$ metformin. The data are mean \pm SEM of 4 animals, the dotted line represents the control group, $* p<0.05$ versus control group, ${ }^{\#} p<0.05$ versus LPS group and ${ }^{\$} p<0.05$ versus $1 \mu \mathrm{M}$ MET group. (Two-way ANOVA followed by Bonferroni) 
The improvement in glucose homeostasis showed in the HFDM could be explained by decreased in weight gain, associated with increased in adiponectin content and huge increased in anti-inflammatory cytokines (IL-1RA, IL-10 and IL-4) induced by metformin treatment in HFD mice.

We observed a decrease in NAFLD in mice submitted to a HFD and treated with metformin confirmed by histological analysis. AMPK protein expression in the liver was increased in the HFDM group. Also, the phosphorylated AMPK (THR 172) had suppressed expression of lipogenesis-associated genes like fatty acid synthase, and phosphorylated ACC, thus deactivating them (Foretz and Viollet 2011; Viollet et al. 2009). Although the ACC did not increase significantly in the HFDM group, there was a trend observed. ACC is an enzyme that controls the synthesis of malonyl-CoA, which is a precursor for the biosynthesis of fatty acids and a potent inhibitor of mitochondrial fatty acid oxidation by inhibiting CPT1. Inhibition of ACC by AMPK leads to a decrease in malonyl-CoA content, and a subsequent decrease in fatty acid synthesis and an increase in fatty acid oxidation. Thus, excessive storage of triglycerides in the liver is reduced (Foretz and Viollet 2011; Viollet et al. 2009). The association between the increase in peripheral fatty acid oxidation and the increase of AMPK in the liver led to the decrease of NAFLD by metformin.

Furthermore, the chronic utilization of low doses of metformin also presents an anti-inflammatory effect in humans, animal models, and in cell culture (Koh et al. 2014; Woo et al. 2014; Xu et al. 2015b).

In our study, $300 \mathrm{mg} / \mathrm{kg}$ of metformin during 10 days promoted a dual inflammatory and anti-inflammatory effect in the retroperitoneal adipose tissue and intraperitoneal macrophages, respectively. Kim et al. 2014, showed that metformin presented an anti-inflammatory action in intraperitoneal macrophages, partially through pathways involving the activation of AMPK and activating transcription factor-3 (ATF-3). A mechanism model shows that ATF-3 inhibits the translocation of NF-kB subunit involved in the transcription of pro-inflammatory genes such as TNF- $\alpha$ and IL-6 (Kim et al. 2014). The potential, anti-inflammatory mechanism through which metformin operates is by the inhibition of NF- $\kappa \mathrm{B}$ through AMPK-dependent and independent pathways (Salminen et al. 2011). Metformin can also increase nitric oxide production and inhibit the poly [ADP ribose] polymerase 1 pathway through AMPK activation, leading to suppression of the inflammatory response. (Saisho 2015).

However, in the liver, metformin caused an inflammatory effect, which was further confirmed with the hepatocyte isolation. It is interesting once a recent study has shown a relationship between inflammation and the progression of NAFLD to steatohepatitis (Wan et al. 2016). However, we observed that the metformin treatment was able to promote a reduction in lipid toxicity and in accumulation in the liver. In according with our findings, the recent metaanalysis showed that the metformin administration reduced the serum levels of glucose and lipids with the improvement of biochemistry parameters, but induced lobular inflammation after metformin treatment in humans (Said and Akhter 2017).

In conclusion, the short-term metformin treatment reversed lipid accumulation in liver by central and peripheral oxidation, improved the glucose homeostasis, ameliorated the inflammation in adipose tissue and intraperitoneal macrophages, but leads to an inflammatory response in liver through an increase in cytokine production by hepatocytes.

Acknowledgements To the funding sources, Fundação de Amparo à Pesquisa do Estado de São Paulo (FAPESP, Brazil) process number 2013/09367-4, 2015/16777-0 and 2016/01409-8, and the Coordenação de Aperfeiçoamento de Pessoal de Nível Superior (CAPES, Brazil).

\section{Compliance with ethical standards}

Conflict of interest The authors declare that there is no conflict of interests regarding the publication of this paper.

\section{References}

Adams LA, Angulo P, Lindor KD (2005) Nonalcoholic fatty liver disease. CMAJ 172:899-905. https://doi.org/10.1503/cmaj.045232

Bergmeyer H, Bernet E (1974) Determination of glucose with glucoseoxidase and peroxidase. In: Bergmeyer $\mathrm{H}$ (ed) Methods of enzymatic analysis. Academic Press, New York, pp 1205-1215

Berlanga A, Guiu-Jurado E, Porras JA, Auguet T (2014) Molecular pathways in non-alcoholic fatty liver disease. Clin Exp Gastroenterol 7:221-239. https://doi.org/10.2147/CEG.S62831

Bi Y et al (2013) The beneficial effect of metformin on beta-cell function in non-obese Chinese subjects with newly diagnosed type 2 diabetes. Diabetes Metab Res Rev 29:664-672. https://doi. org/10.1002/dmrr.2443

Bogachus LD, Turcotte LP (2010) Genetic downregulation of AMPKalpha isoforms uncovers the mechanism by which metformin decreases FA uptake and oxidation in skeletal muscle cells. Am J Physiol Cell Physiol 299:C1549-1561. https://doi.org/10.1152/ ajpcell.00279.2010

Brestoff JR, Artis D (2015) Immune regulation of metabolic homeostasis in health and disease. Cell 161:146-160. https://doi. org/10.1016/j.cell.2015.02.022

Casas R, Sacanella E, Estruch R (2014) The immune protective effect of the mediterranean diet against chronic low-grade inflammatory diseases. Endocr Metab Immune Disord Drug Targets 14:245-254

Challiss RA, Espinal J, Newsholme EA (1983) Insulin sensitivity of rates of glycolysis and glycogen synthesis in soleus, stripped soleus, epitrochlearis, and hemi-diaphragm muscles isolated from sedentary rats. Biosci Rep 3:675-679

Chen M, Zhang J, Liu S, Zhou Z (2015) Effects of metformin on the polarization and Notch 1 expression of RAW264.7 macrophages. Zhonghua Yi Xue Za Zhi 95:1258-1261

Chomczynski P, Sacchi N (1987) Single-step method of RNA isolation by acid guanidinium thiocyanate-phenol-chloroform extraction. Anal Biochem 162:156-159. https://doi.org/10.1006/ abio.1987.9999 
de Morais H, Cassola P, Moreira CC, Bôas SK, Borba-Murad GR, Bazotte RB, de Souza HM (2012) Decreased response to cAMP in the glucose and glycogen catabolism in perfused livers of Walker-256 tumor-bearing rats. Mol Cell Biochem 368:9-16. https://doi.org/10.1007/s11010-012-1337-4

Edwards M, Houseman L, Phillips IR, Shephard EA (2013) Isolation of mouse hepatocytes. Methods Mol Biol 987:283-293. https:// doi.org/10.1007/978-1-62703-321-3_24

Espinal J, Challiss RA, Newsholme EA (1983) Effect of adenosine deaminase and an adenosine analogue on insulin sensitivity in soleus muscle of the rat. FEBS Lett 158:103-106

Fader KA et al (2015) 2,3,7,8-Tetrachlorodibenzo-p-Dioxin alters lipid metabolism and depletes immune cell populations in the Jejunum of C57BL/6 Mice. Toxicol Sci 148:567-580. https:// doi.org/10.1093/toxsci/kfv206

Flannery C, Dufour S, Rabol R, Shulman GI, Petersen KF (2012) Skeletal muscle insulin resistance promotes increased hepatic de novo lipogenesis, hyperlipidemia, and hepatic steatosis in the elderly. Diabetes 61:2711-2717. https://doi.org/10.2337/ db12-0206

Foretz M, Viollet B (2011) Regulation of hepatic metabolism by AMPK. J Hepatol 54:827-829. https://doi.org/10.1016/j. jhep.2010.09.014

Hirabara SM et al (2006) Acute effect of fatty acids on metabolism and mitochondrial coupling in skeletal muscle. Biochim Biophys Acta 1757:57-66. https://doi.org/10.1016/j.bbabio.2005.11.007

Kelly B, Tannahill GM, Murphy MP, O'Neill LA (2015) Metformin inhibits the production of reactive oxygen species from $\mathrm{NADH}$ : ubiquinone oxidoreductase to limit induction of interleukin-1beta (IL-1beta) and boosts Interleukin-10 (IL-10) in Lipopolysaccharide (LPS)-activated Macrophages. J Biol Chem 290:2034820359. https://doi.org/10.1074/jbc.M115.662114

Kim J, Kwak HJ, Cha JY, Jeong YS, Rhee SD, Kim KR, Cheon HG (2014) Metformin suppresses lipopolysaccharide (LPS)-induced inflammatory response in murine macrophages via activating transcription factor-3 (ATF-3) induction. J Biol Chem 289:2324623255. https://doi.org/10.1074/jbc.M114.577908

Kitajima Y et al (2013) Severity of non-alcoholic steatohepatitis is associated with substitution of adipose tissue in skeletal muscle. J Gastroenterol Hepatol 28:1507-1514. https://doi.org/10.1111/ jgh. 12227

Kitzmann M, Lantier L, Hebrard S, Mercier J, Foretz M, Aguer C (2011) Abnormal metabolism flexibility in response to high palmitate concentrations in myotubes derived from obese type 2 diabetic patients. Biochim Biophys Acta 1812:423-430. https://doi. org/10.1016/j.bbadis.2010.12.007

Koh SJ, Kim JM, Kim IK, Ko SH, Kim JS (2014) Anti-inflammatory mechanism of metformin and its effects in intestinal inflammation and colitis-associated colon cancer. J Gastroenterol Hepatol 29:502-510

Leighton B, Budohoski L, Lozeman FJ, Challiss RA, Newsholme EA (1985) The effect of prostaglandins E1, E2 and F2 alpha and indomethacin on the sensitivity of glycolysis and glycogen synthesis to insulin in stripped soleus muscles of the rat. Biochem $\mathbf{J}$ 227:337-340

Liu $C$ et al (2016) Targeting arginase-II protects mice from highfat-diet-induced hepatic steatosis through suppression of macrophage inflammation. Sci Rep 6:20405. https://doi. org/10.1038/srep20405

Livak KJ, Schmittgen TD (2001) Analysis of relative gene expression data using real-time quantitative PCR and the 2(-Delta Delta $\mathrm{C}(\mathrm{T})$ ) method. Methods 25:402-408. https://doi.org/10.1006/ meth.2001.1262

Love-Osborne KA, Nadeau KJ, Sheeder J, Fenton LZ, Zeitler P (2008) Presence of the metabolic syndrome in obese adolescents predicts impaired glucose tolerance and nonalcoholic fatty liver disease. J Adolesc Health 42:543-548. https://doi.org/10.1016/j. jadohealth.2007.11.136

McCullough AJ (2004) The clinical features, diagnosis and natural history of nonalcoholic fatty liver disease. Clin Liver Dis 8:521-533. https://doi.org/10.1016/j.cld.2004.04.004

McNelis JC, Olefsky JM (2014) Macrophages, immunity, and metabolic disease. Immunity 41:36-48. https://doi.org/10.1016/j. immuni.2014.05.010

Mikami Y et al (2014) Macrophages and dendritic cells emerge in the liver during intestinal inflammation and predispose the liver to inflammation. PLoS ONE 9:e84619. https://doi.org/10.1371/ journal.pone.0084619

Moon JS, Yoon JS, Won KC, Lee HW (2013) The role of skeletal muscle in development of nonalcoholic Fatty liver disease. Diabetes Metab J 37:278-285. https://doi.org/10.4093/ dmj.2013.37.4.278

Nasri H, Rafieian-Kopaei M (2014) Metformin: current knowledge. J Res Med Sci 19:658-664

Nati M, Haddad D, Birkenfeld AL, Koch CA, Chavakis T, Chatzigeorgiou A (2016) The role of immune cells in metabolism-related liver inflammation and development of non-alcoholic steatohepatitis (NASH). Rev Endocr Metab Disord. https://doi.org/10.1007/ s11154-016-9339-2

Patane G, Piro S, Rabuazzo AM, Anello M, Vigneri R, Purrello F (2000) Metformin restores insulin secretion altered by chronic exposure to free fatty acids or high glucose: a direct metformin effect on pancreatic beta-cells. Diabetes 49:735-740

Reeves PG, Nielsen FH, Fahey GC Jr (1993) AIN-93 purified diets for laboratory rodents: final report of the American Institute of Nutrition ad hoc writing committee on the reformulation of the AIN-76A rodent diet. J Nutr 123:1939-1951

Said A, Akhter A (2017) Meta-analysis of randomized controlled trials of pharmacologic agents in non-alcoholic steatohepatitis. Ann Hepatol 16:538-547. https://doi.org/10.5604/01.3001.0010.0284

Saisho Y (2015) Metformin and inflammation: its potential beyond glucose-lowering effect. Endocr Metab Immune Disord Drug Targets 15:196-205

Salminen A, Hyttinen JM, Kaarniranta K (2011) AMP-activated protein kinase inhibits NF-kappaB signaling and inflammation: impact on healthspan and lifespan. J Mol Med (Berl) 89:667-676. https://doi.org/10.1007/s00109-011-0748-0

Souza-Mello V, Gregorio BM, Cardoso-de-Lemos FS, de Carvalho L, Aguila MB, Mandarim-de-Lacerda CA (2010) Comparative effects of telmisartan, sitagliptin and metformin alone or in combination on obesity, insulin resistance, and liver and pancreas remodelling in C57BL/6 mice fed on a very high-fat diet. Clin Sci (Lond) 119:239-250. https://doi.org/10.1042/CS20100061

Spruss A, Kanuri G, Stahl C, Bischoff SC, Bergheim I (2012) Metformin protects against the development of fructose-induced steatosis in mice: role of the intestinal barrier function. Lab Invest 92:1020-1032. https://doi.org/10.1038/labinvest.2012.75

Teixeira AA et al (2016) Aerobic exercise modulates the free fatty acids and inflammatory response during obesity and cancer cachexia. Crit Rev Eukaryot Gene Expr 26:187-198. https://doi. org/10.1615/CritRevEukaryotGeneExpr.2016016490

Tiniakos DG, Vos MB, Brunt EM (2010) Nonalcoholic fatty liver disease: pathology and pathogenesis. Annu Rev Pathol 5:145171. https://doi.org/10.1146/annurev-pathol-121808-102132

VanSaun MN, Lee IK, Washington MK, Matrisian L, Gorden DL (2009) High fat diet induced hepatic steatosis establishes a permissive microenvironment for colorectal metastases and promotes primary dysplasia in a murine model. Am J Pathol 175(1):355-364

Vasamsetti SB, Karnewar S, Kanugula AK, Thatipalli AR, Kumar JM, Kotamraju S (2015) Metformin inhibits monocyte-tomacrophage differentiation via AMPK-mediated inhibition of 
STAT3 activation: potential role in atherosclerosis. Diabetes 64:2028-2041. https://doi.org/10.2337/db14-1225

Viollet B et al (2009) Targeting the AMPK pathway for the treatment of Type 2 diabetes. Front Biosci (Landmark Ed) 14:3380-3400

Wan X, Xu C, Yu C, Li Y (2016) Role of NLRP3 inflammasome in the progression of NAFLD to NASH. Can J Gastroenterol Hepatol 2016:6489012. https://doi.org/10.1155/2016/6489012

Wang C et al (2014) Metformin suppresses lipid accumulation in skeletal muscle by promoting fatty acid oxidation. Clin Lab 60:887-896

Woo SL et al (2014) Metformin ameliorates hepatic steatosis and inflammation without altering adipose phenotype in diet-induced obesity. PLoS ONE 9:e91111. https://doi.org/10.1371/journ al.pone.0091111
Xu L, Kitade H, Ni Y, Ota T (2015a) Roles of chemokines and chemokine receptors in obesity-associated insulin resistance and nonalcoholic fatty liver disease. Biomolecules 5:1563-1579. https ://doi.org/10.3390/biom5031563

$\mathrm{Xu}$ W et al (2015b) Metformin ameliorates the proinflammatory state in patients with carotid artery atherosclerosis through sirtuin 1 induction. Transl Res 166:451-458. https://doi.org/10.1016/j. trs1.2015.06.002

Yadav UC, Ramana KV (2013) Regulation of NF-kappaB-induced inflammatory signaling by lipid peroxidation-derived aldehydes. Oxid Med Cell Longev 2013:690545. https://doi. org/10.1155/2013/690545 